\title{
Sap flow, leaf-level gas exchange and spectral responses to drought in Pinus sylvestris, Pinus pinea and Pinus halepensis
}

\author{
José Antonio Manzanera ${ }^{(1)}$, \\ Aranzazu Gómez-Garay ${ }^{(2)}$, \\ Beatriz Pintos ${ }^{(2)}$, \\ Manuel Rodríguez-Rastrero ${ }^{(3)}$, \\ Eugenio Moreda ${ }^{(2)}$, \\ Javier Zazo ${ }^{(1)}$, \\ Eugenio Martínez-Falero ${ }^{(1)}$, \\ Antonio García-Abril ${ }^{(1)}$
}

\begin{abstract}
In a climate change scenario, Mediterranean forest species such as pines may be endangered by rising temperatures and reduced precipitation, thus calling for studies on the transpiration and water balance in pines. In this paper, the response of young plants of Pinus sylvestris L., Pinus pinea L. and Pinus halepensis Mill. to different irrigation treatments has been studied. Significant differences were found in water potential, sap flow, leaf-level gas exchange and spectral variables. $P$. sylvestris had higher pre-dawn and midday water potentials, sap flow rates and leaf-level gas exchange rates compared to the other two species in well-watered conditions. Vapor pressure gradient correlated with stomatal conductance, net assimilation and transpiration, but the association between stomatal conductance and sap flow was weak. The environmental variables more strongly associated with sap flow were solar radiation and reference evapo-transpiration, especially in the well-watered plants, but those associations were weaker in the stressed plants. All three pine species showed the isohydric, drought-avoiding strategy common in the genus Pinus, maintaining relatively high water potentials in dry conditions. Nevertheless, $P$. halepensis showed a water-saving strategy, with a stomatal closure behavior under drought. Stomatal regulation was less strict in $P$. sylvestris, closer to a water-spending pattern, while $P$. pinea showed an intermediate behavior. Significant differences were recorded among species in spectral reflectance in the visible and infra-red regions. Photochemical Reflectance Index, Normalized Difference Vegetation Index and combinations of other ratios permitted the discrimination among the three pine species. These spectral variables showed association with sap flow rate, water potential and leaflevel gas exchange variables. Both cluster analysis and k-means classification discriminated Scots pine and Aleppo pine in two different groups. On the other hand, Stone pine showed differences in spectral behavior depending on the hydric status of the plants. Well-watered Stone pine plants had the same spectral behavior as Scots pine, while the plants subjected to drought stress were closer to Aleppo pine plants in spectral response. These findings may help to quantify the impacts of early and mid-summer water deficit on Mediterranean pines in future climate regimes.
\end{abstract}

Keywords: Carbon Assimilation, Aleppo Pine, Hydric Relations, Reflectance, Scots Pine, Stone Pine, Transpiration

forests in North-Eastern Spain (Martínez-Vilalta \& Piñol 2002), where severe droughtinduced mortality has occurred during recent dry episodes. Similar climate change scenarios have been described in other parts of the world, for instance in the east- ern Mediterranean basin (Ungar et al. 2013) and in the Southern United States (Seager et al. 2007). This situation underlines the need for studies on the water balance in plants from endangered ecosystems, in particular, the regulation of the hydric sta-

(1) Technical University of Madrid, College of Forestry and Natural Environment, Ciudad Universitaria, Moncloa Campus of International Excellence, 28040 Madrid (Spain); (2) Complutense University of Madrid, Dept. of Plant Physiology, Ciudad Universitaria, Moncloa Campus of International Excellence, 28040 Madrid (Spain); (3) Autonomous University of Madrid, Madrid (Spain)

@ José Antonio Manzanera (joseantonio.manzanera@upm.es)

Received: Jun 24, 2015 - Accepted: Jul 16, 2016

Citation: Manzanera JA, Gómez-Garay A, Pintos B, Rodríguez-Rastrero M, Moreda E, Zazo J, Martínez-Falero E, García-Abril A (2017). Sap flow, leaf-level gas exchange and spectral responses to drought in Pinus sylvestris, Pinus pinea and Pinus halepensis. iForest 10: $204-214$. doi: 10.3832/ifor1748-009 [online 2016-11-01] 
tus and transpiration of the dominant woody vegetation. In other Mediterranean and semi-arid ecosystems, hydric and gas exchange parameters at the leaf level have successfully been used as indicators of the ecophysiological competence of forest species in a changing environment (Manzanera \& Martínez-Chacón 2007).

Plant resistance to drought has been hypothesized to reflect two contrasting physiological strategies: drought avoidance and drought tolerance. The mechanisms of either approach, respectively called isohydric and anisohydric, involve control of stomata and water status (Tardieu \& Simonneau 1998, McDowell et al. 2008). Isohydric plants reduce stomatal conductance in dry conditions, maintaining relatively constant leaf water potential regardless of drought intensity, for instance in Prunus sp. (Tardieu \& Simonneau 1998). In contrast, anisohydric species allow leaf water potential to decrease with water availability; there are good examples among the Cupressaceae (Martínez-Vilalta et al. 2004). Both strategies enable plant survival under drought conditions. However, each has inherent drawbacks that can be fatal in certain conditions. Prolonged reductions of stomatal gas exchange expose isohydric species to carbon depletion, while extreme water potential gradients in anisohydric species result in xylem cavitation and embolism and subsequent hydraulic failure (McDowell et al. 2008).

Scots pine (Pinus sylvestris L.) is one of the most widely distributed forest species in the world, extending from the Siberian taiga to mountainous ecosystems in Southwestern Europe, where it reaches the boundary with semi-arid Mediterranean climate and may be more at risk of aridity in a climate change scenario (Martínez-Vilalta \& Piñol 2002). Stone pine (Pinus pinea L.) is a Mediterranean pine species, present in many south European countries, adapted to semi-arid continental and coastal locations, from the sea-level to about $1000 \mathrm{~m}$ altitude. Stone pine prefers sandy acidic soils with good water drainage, and a local annual precipitation between 400 and 800 $\mathrm{mm}$. Aleppo pine (Pinus halepensis Mill.) is another characteristic species of the Mediterranean basin, with preference for basic soils, which shows more resistance to drought, being capable of living with as little as $250 \mathrm{~mm}$ annual precipitation. In spite of the environmental importance of these pine species, there have been few comparative studies aimed at relating the different ecophysiological responses in whole-plant transpiration and in their adaptation to drought (Melzack et al. 1985). Moreover, transpiration of whole-tree water use may be estimated by means of sap flow measurements. One of the most common methods for measuring sap flow is the Thermal Dissipation Probe (TDP) technique, which measures sap flux density in the stem xylem and can then be converted to volumetric flow rate (Granier 1985). Sev- eral studies have related the whole plant transpiration with gas exchange variables at the plant level and with micro-meteorological factors (Oliveras et al. 2003). Furthermore, the spectral features of radiation reflected or transmitted by plants have been used to retrieve their biophysical properties (Ustin et al. 2009), and the spectral behavior of the forest canopy has been successfully linked to physiological variables, for instance detecting forest decline before damage is visible (HernándezClemente et al. 2011).

The spectrum in the visible region (VIS: 400-700 nm) has been associated to high absorption of the photosynthetically active radiation (PAR) by plant pigments, mainly the chlorophylls, while reflectance in the near infrared wavelengths (NIR: 700-1350 $\mathrm{nm}$ ) is determined by the structure of the crown. Water content is the main factor affecting the reflectance in the shortwave infrared wavelengths (SWIR: 1350-2500 nm - Jacquemoud et al. 2009). Spectral methods are based on the association of ecophysiological traits with spectral signatures from which the plant status is inferred, for instance through the inversion of radiative transfer models (Jacquemoud et al. 2009), or using spectral indices (Zarco-Tejada et al. 2005). In this study, we followed the second approach. Several remotely sensed vegetation indices have been used as ecophysiological indicators (Manzanera et al. 2013). These indices are associated with plant water stress (Suárez et al. 2008) or radiation use efficiency (Garbulsky et al. 2011). However, few studies have tried to relate sap flow rates and leaf-level gas exchange variables with spectral indices. Those studies have been restricted to the agricultural sector (Marino et al. 2014) and only very few are focused on the forestry and environmental sector.

A better understanding of the ecophysiology of young plants is important for successful nursery management and for the establishment of new plantations. Therefore, our objectives were: (1) to measure daily sap flow in plants from three pine species present in different ecosystems of the Mediterranean area, namely Scots pine (Pinus sylvestris), stone pine ( $P$. pinea) and Aleppo pine ( $P$. halepensis), and to examine their relationship with environmental conditions such as water availability and evaporative demand; (2) to describe and compare gas exchange responses to different water availabilities, defining and comparing the ecophysiological strategies to face drought adopted by the three pine species; (3) to measure hyperspectral reflectance and compare the spectral behavior of all three species in relation to water availability and to ecophysiological variables such as sap flow rate, water potential and leaflevel gas exchange variables; (4) to predict ecophysiological variables by means of the plant spectral behavior; and (5) to identify possible differences between ecophysiological attributes to explore management implications in the context of a climatechange scenario of increasing aridity.

\section{Materials and methods}

\section{Plant materials}

In all experiments, three pine species were used, i.e., Pinus halepensis, P. pinea and $P$. sylvestris. All the plants were ca. 10 years old, collected from a nursery. Eight plants per species were used, four of which were subjected to a high irrigation regime and four to a low irrigation regime. Thus, a total of 12 plants received a high irrigation dose and 12 a low irrigation dose. Besides, plants also received natural rainfall during the measurement period, although the amount was negligible $(25.4 \mathrm{~mm}$ from May 10 to September 11). All plants were transferred to $15 \mathrm{~L}$ plastic pots ( $7 \mathrm{dm}^{3}$ area) with a mixture (1:1) of peat and soil and placed in a nursery. Plants were allowed to establish good root contact with the substrate for 15 days before the experiment started. The experiment started on May 10, and ended on September 11. For each plant, the diameter was measured at the base of the stem and used to calculate the mean cross sectional area at the base of the stem. The total leaf area $\left(\mathrm{Al}, \mathrm{m}^{2}\right)$ of each plant was estimated using the diameter as independent variable in the allometric equations developed by Montero et al. (2005) for P. sylvestris and $P$. pinea, and by Mitsopoulos \& Dimitrakopoulos (2007) for P. halepensis. Plant size at the beginning of the experiment is given in Tab. S1 (Supplementary material).

\section{Experimental design and \\ measurements}

Two irrigation doses were applied throughout the experiment duration. The high dose consisted of $7 \mathrm{~mm}^{\text {day }}{ }^{-1}$ through an automatic dripping system. One irrigation event was given per day, at 6 a.m. solar time. The low dose was $3.5 \mathrm{~mm}^{\text {day }}{ }^{-1}$, in the same conditions.

Sap flow was determined using the thermal dissipation probe (TDP) technique (Granier 1985). Briefly, this system consists of two thermocouple probes which are inserted into the plant sapwood, one directly above the other, at a distance of 4 $\mathrm{cm}$ each other. The upper probe contains an electrical heater. The thermocouples measure the temperature difference $(d T)$ between the heated probe and the sapwood temperature below. Then, $d T$ will decrease as the flowing sap cools the heated needle. The $d T$ variable and the daily maximum $(\mathrm{dTm})$ at zero flow are used to estimate sap flux density and therefore whole-tree transpiration. In our experiment, a TDP30 Dynamax ${ }^{\circledR}$ (Houston, TX, USA) thermal dissipation probe was inserted in the stem of each plant, at about $10 \mathrm{~cm}$ height from the base. We checked that the sensing zone of the probe was in full contact with the xylem of the plant. Then the area between the upper and 
lower probe was isolated with styrofoam eggs and shielded with aluminium reflective bubble foil cover to minimize natural temperature gradients and provide thermal insulation and mechanical protection, according to the vendor instructions. The TDP probes were connected to a Dynamax Probe 12 biomonitor. The upper probe of each sensor was supplied permanently with a constant power of 0.15 to $0.2 \mathrm{~W}$, while the lower probe was unheated for reference. Sap flow data were recorded and estimated according to Granier (1985), from May $10^{\text {th }}$ to September $11^{\text {th }} 2012$. From the hourly recorded dataset, two sap flowbased variables were calculated: mean sap flow of the growing season $\left(F, \mathrm{~g} \mathrm{~h}^{-1}-\right.$ eqn. 1) and mean sap flow velocity $\left(v, \mathrm{~cm} \mathrm{~s}^{-1}-\right.$ eqn. 2).

$$
F=A s \cdot 3600 s h^{-1} \cdot v
$$

where $F$ is the sap flow $\left(\mathrm{g} \mathrm{h}^{-1}\right)$ and $A s$ is the cross-sectional area of sap conducting wood $\left(\mathrm{cm}^{2}\right)$. Given the age of the plants, we considered that the sapwood area equaled the whole cross section. The sap flow velocity $v\left(\mathrm{~cm} \mathrm{~s}^{-1}\right)$ was estimated according to the empirical formula by Granier (1985 - eqn. 2):

$$
v=0.0119\left(\frac{d T m-d T}{d T}\right)^{1.231}
$$

where $d T$ is the measured difference in temperature between that of the heated probe, referenced to the lower non-heated probe, and $d T m$ is the daily maximum $d T$ at zero flow.

Water potential was measured in all plants with a PMS pressure bomb at dawn and at midday. Three needles were measured per plant and the average water potential was calculated per plant. Measurements were taken on June $26^{\text {th }}$, August $17^{\text {th }}$ and September $24^{\text {th }} 2012$, trying to represent the hydric status in the first month, mid-season and the end of the dry period, respectively.

Leaf-level gas exchange variables, i.e., net assimilation (An), transpiration (E), stomatal conductance $\left(\mathrm{g}_{\mathrm{s}}\right)$, internal $\mathrm{CO}_{2}$ concentration $\left(C_{i}\right)$, water use efficiency (WUE), intrinsic water use efficiency (IWUE), leaf-toair vapor pressure gradient (VPG) and photosynthetic photon flux density (PPFD) were recorded with a Delta $T$ Infrared Gas Analyzer (IRGA) and a conifer chamber, in the middle (August 20 $0^{\text {th }}, 2012$ ) and the end (October $3^{\text {rd }}$ ) of the dry season, in outdoors environmental conditions. During measurements (12:00 to 16:00 h), the average PPFD ranged from 150 to $201 \mu \mathrm{mol} \mathrm{m} \mathrm{m}^{-2} \mathrm{~s}^{-1}$. Average leaf chamber $\mathrm{CO}_{2}$ concentration and temperature ranged from 393 to $400 \mathrm{ppm}$ and from 30 to $35.6{ }^{\circ} \mathrm{C}$, respectively. After gas exchange measurements, the projected needle area was estimated with an image analyzer, and the gas exchange variables were referred to the measured needle area.
Spectral signatures were recorded from all 24 plants with an ASD FieldSpec $3^{\oplus}$ (Analytical Spectral Devices Inc., Boulder, CO, USA) field spectroradiometer. Measurements were always made in clear sky conditions, on June $25^{\text {th }}$ and July $2^{\text {nd }}, 2012$, at midday, operating in the spectral range between 350 and $2500 \mathrm{~nm}$ with an average spectral resolution of $3 \mathrm{~nm}$ FWHM (FullWidth-Half-Maximum) and a sampling interval of $1.4 \mathrm{~nm}$ across the 350-1050 nm spectral range. The FWHM and the sampling interval for the $1051-2500 \mathrm{~nm}$ spectral range are 30 and $2 \mathrm{~nm}$, respectively. A fibre optic cable, providing a field of view edge of $25^{\circ}$, was connected to the spectroradiometer to collect reflectance spectra in nadir direction. Three signatures were recorded per plant from their tops, and the average was used to estimate the spectral response. Before and between every series of three plant reflectance measurements, three white references were taken for calibration, by measuring the reflectance of a $1 \times 1 \mathrm{~m}$ polystyrene panel, covered with a mixture of barium sulphate powder and white paint, as white standard. The ViewSpec Pro ${ }^{\circledast}$ (ASD) software was used for pre-processing reflectance spectra and then reflectance indices were derived. The reflectance responses of all 24 pines used in this experiment were tested for the species and the irrigation treatment. Reflectance in the range from 350 to $2500 \mathrm{~nm}$ wavelength was measured, and spectral indices were calculated to track changes in pigment concentration as a function of the water stress condition: green $(531 \mathrm{~nm})$, yellow $(570 \mathrm{~nm})$, red $(670 \mathrm{~nm})$, different Near Infra-Red (NIR) reflectances: NIR1 (760 $\mathrm{nm}), \mathrm{NIR} 2$ (895 nm), NIR3 (900 nm), NIR4 (970 nm), NIR5 (1090 nm), NIR6 (1190 nm), two Short Wave Infra-Red: SWIR1 (1650 $\mathrm{nm})$, SWIR2 (2217 nm); Normalized Difference Vegetation Index: (NDVI - Rouse et al. 1974), Physiological (or Photochemical) Reflectance Index (PRI - Garbulsky et al. 2011), Normalized Difference Infrared Index (NDII - Hardisky et al. 1983); different indices based on reflectance ratios: SWIR1/SWIR2, simple ratio (SR) $=$ NIR5/Red (Rondeaux et al. 1996), SWIR1/Red, SWIR2/Red (see Tab. S2 in Supplementary material), and the Global Environmental Monitoring Index (GEMI - Pinty \& Verstraete 1992), the latter being calculated according to the formula (eqn. 3 ):

$$
G E M I=\eta(1-0.25 \eta)-\frac{\operatorname{Red}-0.125}{1-\operatorname{Red}}
$$

\section{where $\eta$ is (eqn. 4):}

$$
\eta=\frac{2 \mathrm{NIR}^{2}-\mathrm{Red}^{2}+1.5 \mathrm{NIR} 5+0.5 \mathrm{Red}}{\mathrm{NIR} 5+\operatorname{Red}+0.5}
$$

Micrometeorological variables were recorded with a Davis Vantage Pro2 ${ }^{\mathrm{TM}}$ (Davis Instruments, CA, USA) meteorological station every five minutes, during all the experiment duration. Temperature $\left({ }^{\circ} \mathrm{C}\right)$, rel- ative air humidity ( $\mathrm{rH}, \%)$, vapour pressure deficit (VPD), solar radiation $\left(\mathrm{W} \mathrm{m}^{-2}\right.$ ), wind speed $\left(\mathrm{m} \mathrm{s}^{-1}\right)$, barometric pressure $(\mathrm{hPa})$, rain rate $\left(\mathrm{mm} \mathrm{h}^{-1}\right)$, soil moisture $(\mathrm{kPa})$ at 5 and $15 \mathrm{~cm}$ depth and soil temperature $\left({ }^{\circ} \mathrm{C}\right)$ at 5 and $15 \mathrm{~cm}$ depth were averaged per hour. Rainfall $(\mathrm{mm})$ and reference evapotranspiration (ETo, $\mathrm{mm}$ ) were accumulated per hour. Reference evapo-transpiration was estimated according to the modified Penman's equation as implemented by the California Irrigation Management Information System, CIMIS, including Net Radiation calculation (Snyder \& Pruitt 1985).

\section{Statistics}

Tree species, leaf-level variables, irrigation treatments and dates of measurement were compared through multifactor Analysis of Variance (ANOVA). Water potential, sap flow, leaf-level gas exchange variables and spectral indices were also tested through correlation analysis. Significant variables were estimated with regression models. The statistical packages Statgraphics Centurion XVI ${ }^{\oplus}$ v. 16.1.17 (StatPoint Technologies, Warrenton, VA, USA) and STATISTICA v. 7.1 (StatSoft Inc., Tulsa, OK, USA) were used. Several reflectances and spectral indices were compared through ANOVA: green $(531 \mathrm{~nm})$, yellow $(570 \mathrm{~nm})$, red $(670 \mathrm{~nm})$, different Near Infra-Red (NIR) wavelengths: NIR1 (760 nm), NIR5 (1090 nm), NIR6 (1190 nm), two Short Wave Infra-Red: SWIR1 (1650 nm), SWIR2 (2217 nm); Normalized Difference Vegetation Index NDVI5, Photochemical Reflectance Index (PRI), Normalized Difference Infrared Index (NDII), Global Environmental Monitoring Index (GEMI); and different ratios: SWIR1/SWIR2, NIR5/Red, SWIR1/Red, SWIR2/Red.

\section{Results}

The leaf area (Al) per plant was compared before the beginning of the experiment between the two sets of plants which were going to be subjected to the different irrigation treatments by ANOVA, to test possible differences in size which could bias the results. However, no statistically significant differences were found among plants subjected to the irrigation treatments $(\mathrm{p}=$ 0.999), among the three species ( $p=$ 0.460 ) or the interaction between species and treatment $(p=0.467)$. Therefore, we assumed that differences in the results of the experiments carried out cannot be attributed to differences in leaf area among plants (see Tab. S1 in Supplementary material). On the other hand, stone pine plants had a significantly larger ( $\mathrm{p} \leq$ 0.0001 ) cross sectional area (As) than the other two species, due to the intrinsic anatomical traits of stone pine. As a consequence, significant differences in the leaf area to cross-sectional sapwood area ratio (Al:As) were found $(p=0.026)$. The Al:As ratio of stone pine was significantly lower than in Scots pine but it was not significantly different from that of Aleppo pine 

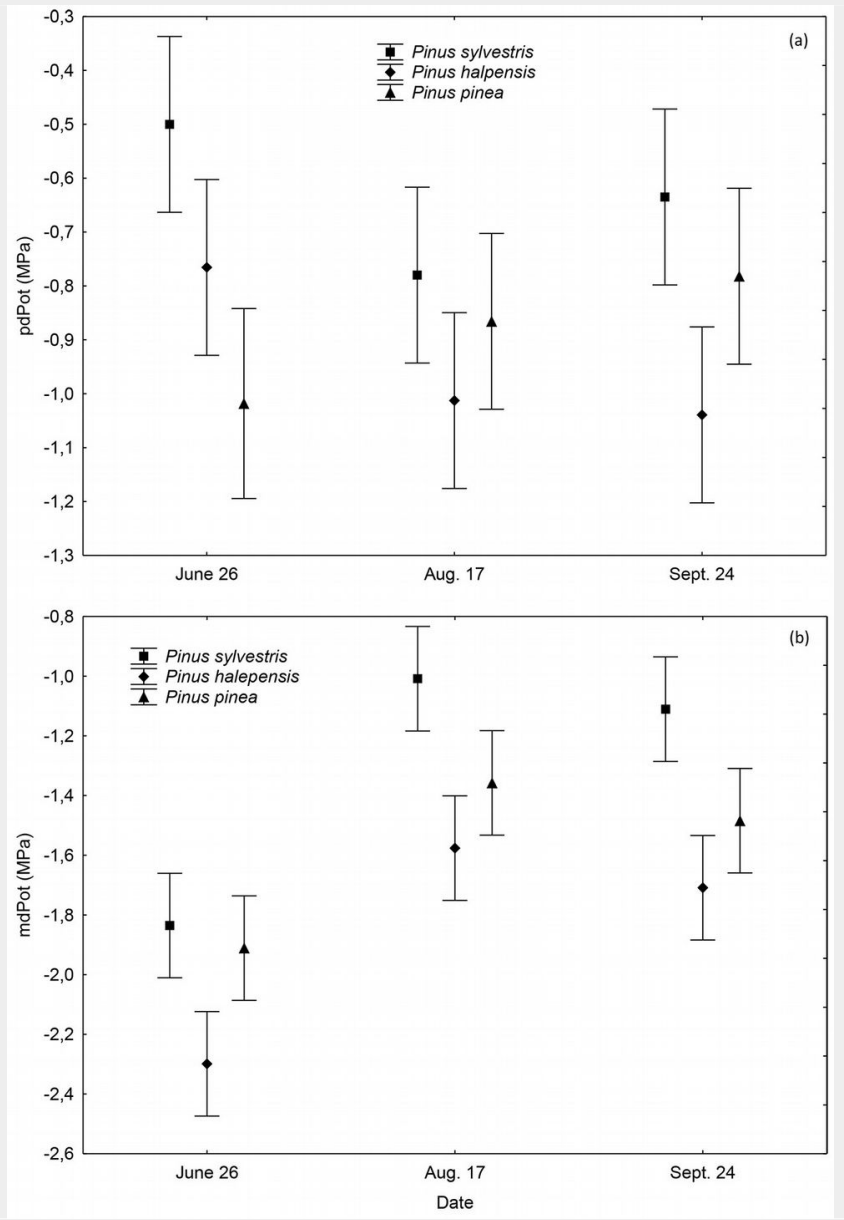

Fig. 1 - (a) Mean pre-dawn leaf water potential (pdPot, MPa) and (b) Midday water potential (mdPot, MPa) in Pinus sylvestris, $P$. halepensis and $P$. pinea. Plants were subjected to two irrigation regimes, high irrigation $\left(7 \mathrm{~mm} \mathrm{day}^{-1}\right)$ and low irrigation (3.5 mm day ${ }^{-1}$ ) from June to September. Vertical bars denote $95 \%$ confidence intervals.
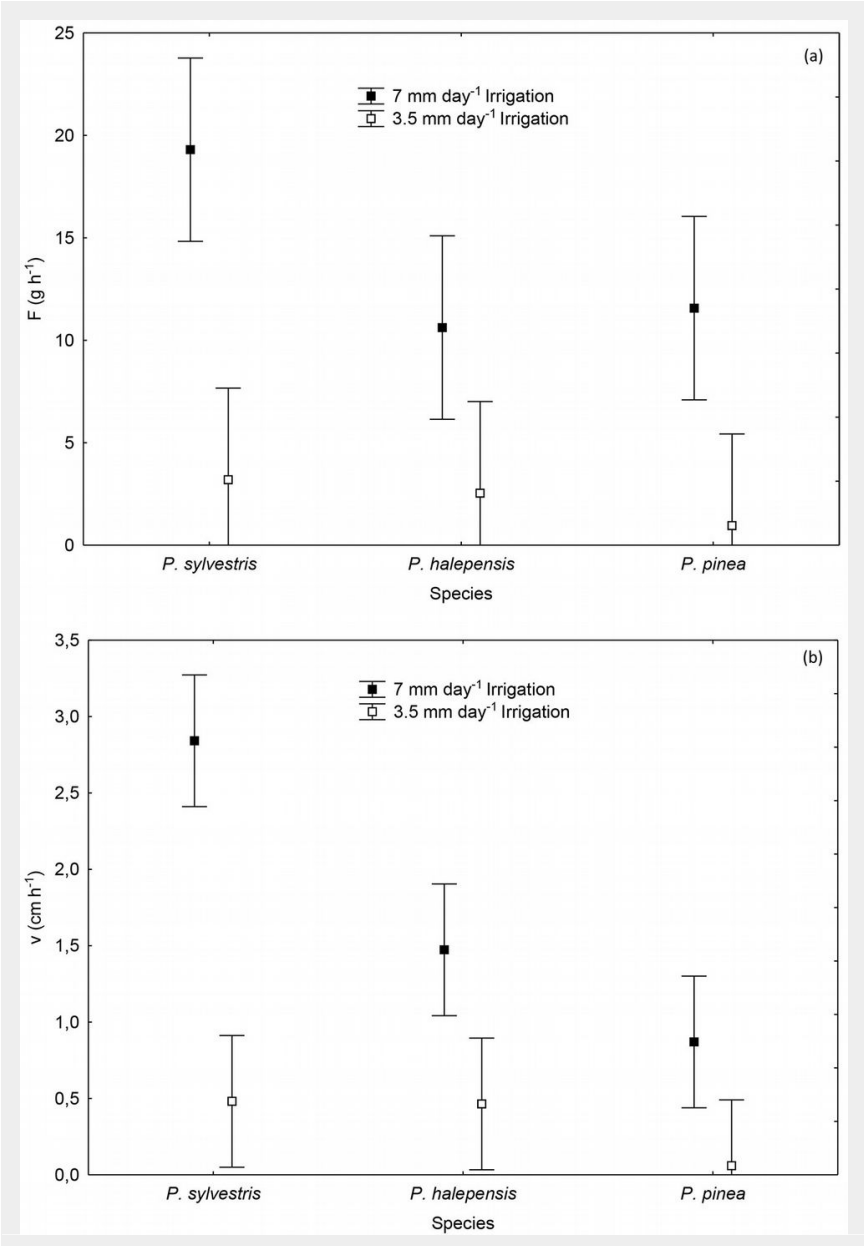

Fig. 2 - (a) Mean sap flow rate $\left(F, g h^{-1}\right)$ and (b) mean sap-flow velocity $\left(v, \mathrm{~cm} \mathrm{~h}^{-1}\right)$ in Pinus sylvestris, $P$. halepensis and $P$. pinea plants subjected to two irrigation regimes: high irrigation (7 $\mathrm{mm} \mathrm{day}^{-1}$ ) and low irrigation $\left(3.5 \mathrm{~mm}\right.$ day $\left.^{-1}\right)$. Vertical bars represent $95 \%$ confidence intervals.
(Tab. S1 in Supplementary material).

Observed climatic conditions over the study period (temperatures, precipitation, and air relative humidity) were compared with average conditions from the 19822010 period (Tab. S3 in Supplementary material), indicating that May, June and August were warmer and dryer in the study period than the average, while July and September were close to the average.

\section{Water potential}

Significant differences in pre-dawn water potential were found for the interaction between species and date of measurement $(p=0.020)$. Pinus sylvestris showed the highest pre-dawn water potential as compared to $P$. halepensis, while Pinus pinea was lowest in June, and intermediate in August and September. In this period, the pre-dawn water potential was relatively stable (Fig. 1a).

On the other hand, midday water potential had statistically significant differences between species $(p \leq 0.001)$ and between dates of measurement ( $p \leq 0.001$ - Fig. 1b), but not between the irrigation treatments nor for the interactions. Pinus sylvestris and $P$. pinea plants had the highest midday water potential and $P$. halepensis the lowest, without differences between treatments. Midday water potential was lowest on June $26^{\text {th }}$, especially for Pinus halepensis $(-2.3 \mathrm{MPa})$ and recovered as the season advanced, in parallel with the decreasing temperature and ETo and the increasing $\mathrm{rH}$ (Fig. S1 in Supplementary material). Pinus pinea had an initial water potential (-1.91 $\mathrm{MPa}$ ) closer to Pinus sylvestris (-1.84 MPa), but did not recover to the same high levels in August and September (Fig. 1b).

\section{Sap flow measurements}

Mean sap flow rate of the whole season was only significantly different among irrigation treatments ( $p \leq 0.001-$ Fig. $2 a)$ but not among species or for the interaction. On the other hand, mean sap-flow velocity showed significant differences for the irrigation treatment $(p \leq 0.001)$, species $(p \leq$ 0.001 ) and the interaction ( $p=0.003-$ Fig. $2 b$ ). As expected, sap flow rate and mean sap-flow velocity were higher in the more watered plants. Pinus sylvestris had higher mean sap flow rate than the other two species with more irrigation, but the rate was reduced to approximately the same level as the other two pine species when less water was available (Fig. 2a). On the other hand, correlation analysis did not show significant relationships between water potential and sap flow either.

\section{Leaf-level gas exchange variables}

ANOVA of leaf-level gas exchange variables revealed significant differences in net assimilation rate (An) among species ( $p=$ 0.044 ) and dates of measurement ( $p \leq$ $0.001)$ but not for the interactions. During the adverse period of August, net assimilation was lower for all species, but as temperatures descended, P. sylvestris showed a better capacity of recovery by a higher assimilation rate than the other pines.

Transpiration rate $\left(\mathrm{E}, \mathrm{mmol} \mathrm{m} \mathrm{m}^{-2} \mathrm{~s}^{-1}\right)$ was significantly lower in August than in October $(p \leq 0.001)$ and for the interaction between species and irrigation treatment $(p=$ 0.035 - Fig. S2a in Supplementary material). As for net assimilation, transpiration showed a depression in August, while in 
Tab. 1 - Correlation coefficients between leaf-level gas exchange variables (An: net assimilation; E: transpiration rate; gs: stomatal conductance; $\mathrm{C}_{\mathrm{i}}$ : internal $\mathrm{CO}_{2}$ concentration; VPG: vapor pressure gradient; IWUE: intrinsic water use efficiency), midday water potential (mdPot) and daily sap flow rate (Sap Flow) during August and September. Values of the second row for each variable are the significance values (prob, in italic). $\left(^{*}\right): p \leq 0.05 ;(* *): p \leq 0.01 ;(* *): p \leq 0.001$.

\begin{tabular}{llllllll}
\hline Parameter & E & g $_{s}$ & $C_{i}$ & mdPot & VPG & IWUE & Sap Flow \\
\hline An & $0.798^{* * *}$ & $0.848^{* * *}$ & 0.072 & 0.122 & $-0.633^{* * *}$ & 0.268 & 0.266 \\
prob & 0.000 & 0.000 & 0.640 & 0.432 & 0.000 & 0.079 & 0.081 \\
E & - & $0.897^{* * *}$ & 0.138 & 0.113 & $-0.574^{* * *}$ & -0.089 & 0.209 \\
prob & - & 0.000 & 0.373 & 0.463 & 0.000 & 0.566 & 0.174 \\
gs & - & - & $0.328^{*}$ & 0.039 & $-0.765^{* * *}$ & -0.158 & $0.306^{*}$ \\
prob & - & - & 0.030 & 0.802 & 0.000 & 0.305 & 0.043 \\
C & - & - & - & -0.100 & $-0.410^{* *}$ & $-0.515^{* * *}$ & 0.211 \\
prob & - & - & - & 0.517 & 0.006 & 0.000 & 0.169 \\
mdPot & - & - & - & - & 0.062 & -0.037 & $0.447^{* *}$ \\
prob & - & - & - & - & 0.691 & 0.814 & 0.002 \\
\hline
\end{tabular}

Tab. 2 - Linear correlation coefficients between meteorological variables and mean sap flow per species (Pinus sylvestris, P. halepensis, P. pinea) and irrigation treatment (high irrigation: $7 \mathrm{~mm}$ day ${ }^{-1}$; low irrigation: $\left.3.5 \mathrm{~mm}^{\text {day }}{ }^{-1}\right)$. (T): air temperature; $(\mathrm{rH})$ : relative humidity; (VPD): vapour pressure deficit; (Rad): solar radiation; (ETo): reference evapo-transpiration; (sylv-Highlrr): sap flow of Pinus sylvestris with high irrigation; (halep-Highlrr): sap flow of $P$. halepensis with high irrigation; (pinea-Highlrr): sap flow of $P$. pinea with high irrigation; (Sylv-Lowlrr): sap flow of Pinus sylvestris with low irrigation; (halep-Lowlrr): sap flow of $P$. halepensis with low irrigation; (pinea-Lowlrr): sap flow of $P$. pinea with low irrigation. Values of the second row for each variable are the significance values (prob, in italic). $(*): p \leq 0.05 ;(* *): p \leq 0.01 ;(* *): p \leq 0.001$.

\begin{tabular}{|c|c|c|c|c|c|c|c|c|c|c|}
\hline Parameter & $\mathrm{rH}$ & VPD & Rad & ETo & $\begin{array}{l}\text { sylv- } \\
\text { Highlrr }\end{array}$ & $\begin{array}{l}\text { halep- } \\
\text { Highlrr }\end{array}$ & $\begin{array}{l}\text { pinea- } \\
\text { Highlrr }\end{array}$ & $\begin{array}{l}\text { sylv- } \\
\text { Lowlrr }\end{array}$ & $\begin{array}{l}\text { halep- } \\
\text { Lowlrr }\end{array}$ & $\begin{array}{l}\text { pinea- } \\
\text { Lowlrr }\end{array}$ \\
\hline$T$ & $-0.8197^{*}$ & 0.9527 * & $0.5529 *$ & 0.6842 * & 0.4874 & 0.3889 & 0.4085 & 0.1712 & 0.2635 & -0.0739 \\
\hline prob & 0.0000 & 0.0000 & 0.0000 & 0.0000 & 0.0000 & 0.0000 & 0.0000 & 0.0000 & 0.0000 & 0.0001 \\
\hline VPD & - & - & 0.5446 * & 0.7119 * & 0.4493 & 0.3315 & 0.3553 & 0.0868 & 0.1999 & -0.1176 \\
\hline prob & - & - & 0.0000 & 0.0000 & 0.0000 & 0.0000 & 0.0000 & 0.0000 & 0.0000 & 0.0000 \\
\hline Rad & - & - & - & 0.9015 * & 0.8286 * & 0.7250 * & 0.8068 * & 0.5383 * & 0.6831 * & 0.1305 \\
\hline prob & - & - & - & 0.0000 & 0.0000 & 0.0000 & 0.0000 & 0.0000 & 0.0000 & 0.0000 \\
\hline ETo & - & - & - & - & 0.7248 * & $0.5937^{*}$ & 0.6136 * & 0.3627 & 0.5232 * & -0.0311 \\
\hline prob & - & - & - & - & 0.0000 & 0.0000 & 0.0000 & 0.0000 & 0.0000 & 0.0965 \\
\hline
\end{tabular}

October Pinus sylvestris recovered with a higher $\mathrm{E}$ rate than the other species at the low irrigation treatment (Fig. S2a in Supplementary material). Stomatal conductance also showed significant differences among the dates of measurement $(p \leq 0.001)$ and for the interaction between species and irrigation treatment ( $p=0.009-$ Fig. S2b in Supplementary material). Stomatal conductance followed the same pattern of An and $\mathrm{E}$, as it was higher in October than in August. On the other hand, neither water use efficiency (WUE) nor intrinsic water use efficiency (IWUE) were statistically significant for any of the factors tested.

Correlations among water potential, sap flow and gas exchange variables

Correlation analysis among leaf-level gas exchange variables, water potentials and sap flow rates revealed a general good correlations between pairs of gas exchange variables, between water potentials, or between sap flow rates, but not between variables of different sets. Only An, E and $\mathrm{g}_{s}$ showed good correlations among them and with VPG, and a weak correlation was found between midday water potential and sap flow (Tab. 1). Remarkably, E did not show correlation with sap flow measurements. The best regression model for predicting $g_{s}$ using VPG as predictor variable was the square root- $Y$ reciprocal- $X$ model $\left(p \leq 0.000, r=0.84, R^{2}=71.03 \%-\right.$ eqn. 5):

$$
g_{s}=\left(-3.94985+30.1483 \cdot V P G^{-1}\right)^{2}
$$

\section{Sap flow correlations with}

meteorological variables

Mean sap flow of each species and irrigation treatment were tested for correlations with meteorological data recorded during the experiment duration. Solar radiation had the strongest correlation with mean sap flow, with differences among species (Tab. 2). The high irrigation treatment had better correlation than the low irrigation treatment. Also, ETo was moderately correlated with mean sap flow of the wellwatered pines, but the correlation coefficients decreased for the less irrigated plants. Correlations of VPD with sap flow were weak (Tab. 2). As expected, some meteorological variables were strongly correlated: mean temperature $(T)$ and relative humidity $(\mathrm{rH}), \mathrm{T}$ and ETo, VPD and ETo. However, no good correlations were observed between them or between precipitation and sap flow, except for the men-

Tab. 3 - Mean sap flow rate $\left(\mathrm{F}, \mathrm{g} \mathrm{h}^{-1}\right)$ regression models, with solar radiation $\left(\mathrm{W} \mathrm{m}^{-2}\right)$ as the independent variable, in Pinus sylvestris, Pinus halepensis and Pinus pinea subjected to high irrigation $\left(7 \mathrm{~mm} \mathrm{day}^{-1}\right)$ or low irrigation $\left(3.5 \mathrm{~mm}\right.$ day $\left.{ }^{-1}\right)$. All of them fitted to a double square root model, except for $P$. halepensis with low irrigation, which followed a square root-Y model. Model parameters: b, slope; a, y-intercept.

\begin{tabular}{|c|c|c|c|c|c|}
\hline Species & Irrigation & Regression Model & $r$ & adjusted $\mathrm{R}^{2}$ & p-value \\
\hline P. sylvestris & $7 \mathrm{~mm}$ day $^{-1}$ & eqn. $6 ; a=0.55 ; b=0.239$ & 0.89 & $78.5 \%$ & 0.000 \\
\hline P. halepensis & $7 \mathrm{~mm}$ day $^{-1}$ & eqn. $6 ; a=0.43 ; b=0.165$ & 0.79 & $62.32 \%$ & 0.000 \\
\hline P. pinea & $7 \mathrm{~mm}$ day $^{-1}$ & eqn. $6 ; a=0.43 ; b=0.182$ & 0.86 & $74.09 \%$ & 0.000 \\
\hline P. sylvestris & $3.5 \mathrm{~mm}$ day $^{-1}$ & eqn. $6 ; a=0.44 ; b=0.07$ & 0.63 & $39.46 \%$ & 0.000 \\
\hline P. halepensis & $3.5 \mathrm{~mm}$ day $^{-1}$ & eqn. $7 ; a=0.38 ; b=0.003$ & 0.70 & $49.14 \%$ & 0.000 \\
\hline P. pinea & $3.5 \mathrm{~mm}$ day $^{-1}$ & eqn. $6 ; a=0.54 ; b=0.01$ & 0.15 & $2.31 \%$ & 0.000 \\
\hline
\end{tabular}


Tab. 4 - Correlation coefficients between leaf-level gas exchange variables (An: net assimilation; E: transpiration rate; $\mathrm{g}_{s}$ : stomatal conductance; $\mathrm{C}_{\mathrm{i}}$ : internal $\mathrm{CO}_{2}$ concentration; VPG: vapour pressure gradient), and daily sap flow rate (Sap Flow), during September (Sep) and October (Oct). Values of the second row for each variable are the significance values (prob, in italic). $(*): p \leq 0.05 ;(* *): p \leq 0.01 ;(* * *): p \leq 0.001$.

\begin{tabular}{|c|c|c|c|c|c|}
\hline Parameters & $\begin{array}{c}E \\
(\mathrm{Oct})\end{array}$ & $\begin{array}{l}\mathrm{g}_{\mathrm{s}} \\
\text { (Oct) }\end{array}$ & $\begin{array}{c}C_{i} \\
(O c t)\end{array}$ & $\begin{array}{l}\text { VPG } \\
\text { (Oct) }\end{array}$ & $\begin{array}{l}\text { Sap Flow } \\
\text { (Sep) }\end{array}$ \\
\hline $\begin{array}{l}\text { An (Oct) } \\
\text { prob }\end{array}$ & $0.891^{\text {*** }}$ & $\begin{array}{l}0.898^{* * *} \\
0.000\end{array}$ & $\begin{array}{l}-0.769^{* * *} \\
0.000\end{array}$ & $\begin{array}{c}-0.509 * \\
0.015\end{array}$ & 0.486 * \\
\hline $\mathrm{E}(\mathrm{Oct})$ & 0.000 & $0.995^{* * *}$ & $\begin{array}{l}0.000 \\
-0.561^{* *}\end{array}$ & $\begin{array}{c}0.015 \\
-0.563\end{array}$ ** & $\begin{array}{l}0.022 \\
0.303\end{array}$ \\
\hline prob & - & 0.000 & 0.007 & 0.006 & 0.170 \\
\hline $\mathrm{g}_{\mathrm{s}}$ (Oct) & - & - & -0.616 ** & -0.611 ** & 0.360 \\
\hline prob & - & - & 0.002 & 0.003 & 0.100 \\
\hline$C_{i}($ Oct $)$ & - & - & - & $0.614^{* *}$ & $-0.633^{* *}$ \\
\hline prob & - & - & - & 0.002 & 0.002 \\
\hline
\end{tabular}

Fig. 3 - (a): Photochemical Reflectance Index (PRI);

(b): Short Wave

Infra-Red (reflectance at wave length $1650 \mathrm{~nm}$; SWIR1) to Red $(670 \mathrm{~nm})$ ratio (SWIR1/Red); and (c): Short Wave Infra-Red (reflectance at wavelength $2217 \mathrm{~nm}$; SWIR2) to Red $(670 \mathrm{~nm})$ ratio (SWIR2/Red), of Pinus sylvestris, $P$. halepensis and $P$. pinea subjected to high ( $\left.7 \mathrm{~mm} \mathrm{day}^{-1}\right)$ and low $(3.5 \mathrm{~mm}$

day $^{-1}$ ) irrigation treatments. Vertical bars represent 95\% Least Significant Difference (LSD) intervals.

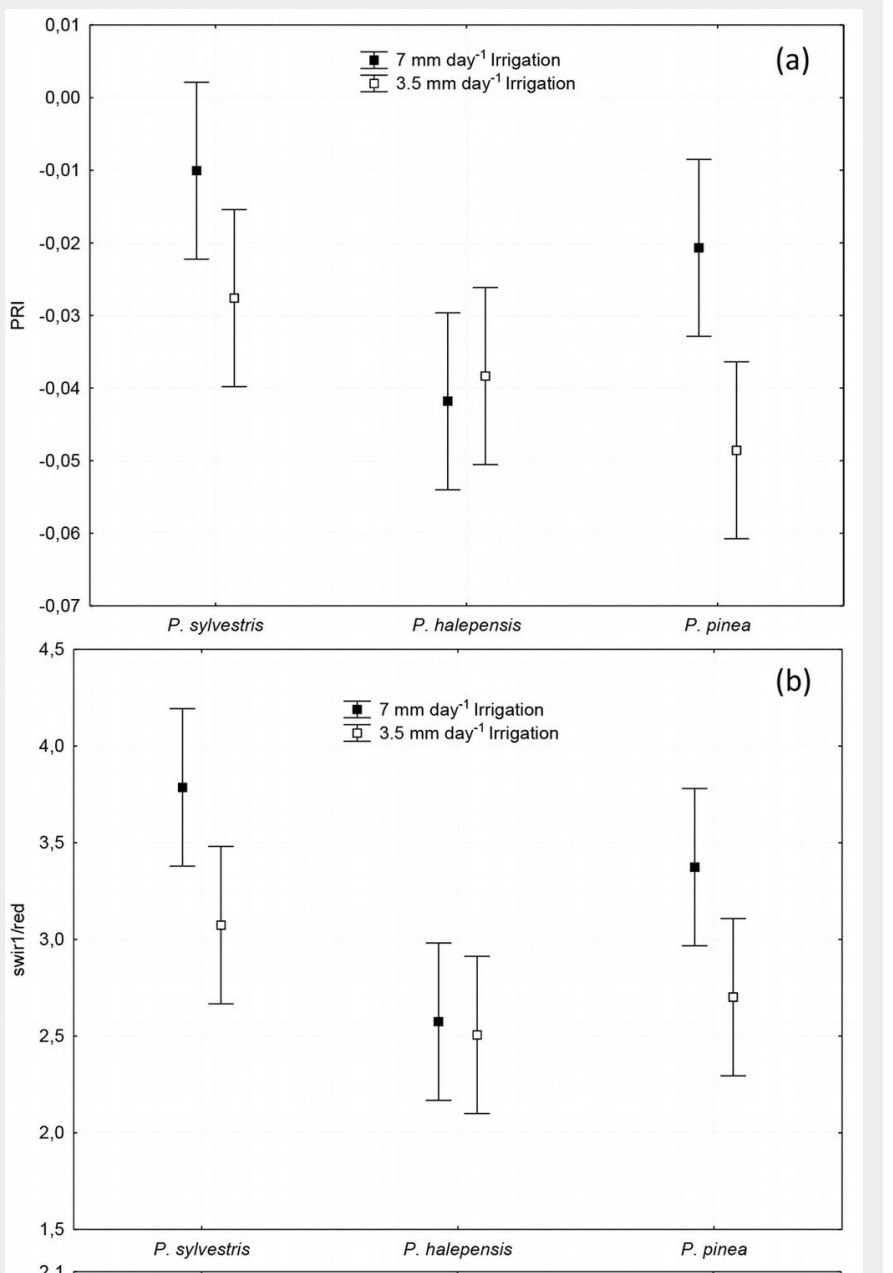

(c)

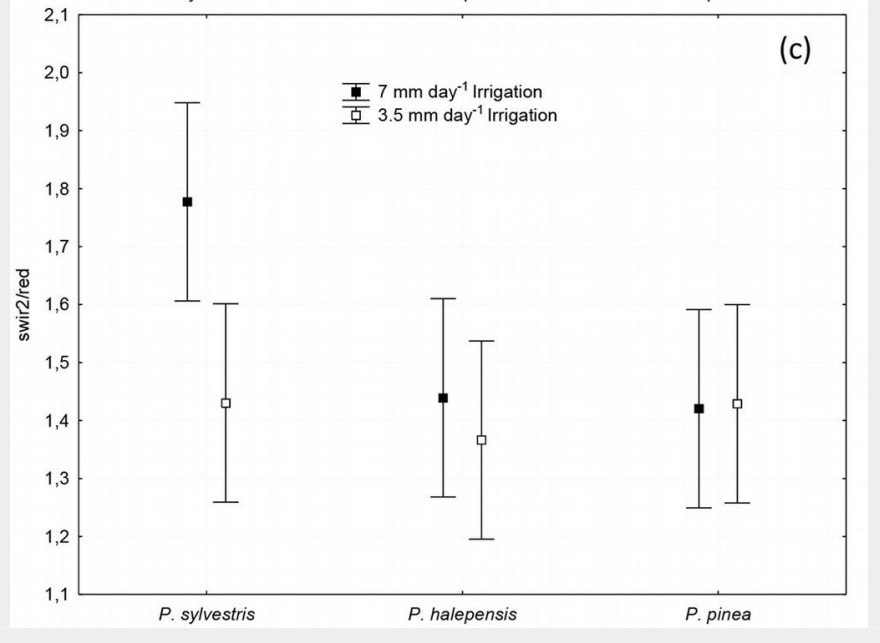

tioned correlation of ETo with sap flow (Tab. 2). Significant regression models predicted sap flow responses with solar radiation as the independent variable for all species and treatments (Tab. 3). In all cases, the best fit was a double square root model (eqn. 6), except for Pinus halepensis subjected to the low irrigation treatment, which followed a quadratic model (eqn. 7):

$$
\begin{gathered}
F=\left(a+b \cdot \operatorname{Rad}^{0.5}\right)^{2} \\
F=(a+b \cdot \operatorname{Rad})^{2}
\end{gathered}
$$

where $a$ and $b$ are the model parameters (Tab. 3).

\section{Seasonal effect on leaf-level gas} exchange and sap flow variables

Again, An, E and gs were highly correlated ( $r=0.89$ to 0.99) while the correlation with the internal $\mathrm{CO}_{2}$ concentration $\mathrm{C}_{i}$ was negative at the end of the growing season (Tab. 4). Sap flow rate was weakly associated with An. A positive correlation of $C_{i}$ in October with VPG of the same day $(r=0.61)$ and a negative one with the sap flow rate of September $(r=-0.63)$ was recorded (Tab. 4). A similar pattern has been observed for the other gas exchange variables: An, E and especially $g_{s}$ show no correlation with VPG in August, but are negatively correlated with VPG in October (Tab. 4).

\section{Analysis of spectral indices}

The spectral reflectance responses of all 24 pines used in this experiment were tested for the species and the irrigation treatment (Fig. S3 in Supplementary material). The spectrum of the well-watered pines (high irrigation, $7 \mathrm{~mm} \mathrm{day}^{-1}$ ) was characterized by a low reflectance $(<0.12)$ in the visible region (VIS: $400-700 \mathrm{~nm}$ ), while in the less irrigated pines $\left(3.5 \mathrm{~mm}^{-1}\right.$ day $\left.^{-1}\right)$ this reflectance was slightly higher. Reflectance in the near infrared wavelengths (NIR: 700-1350 nm) was relatively higher ( $\geq$ 0.3). Gaps between the NIR and SWIR bands are spectral regions affected by the atmospheric moisture and these were omitted.

For green reflectance $(531 \mathrm{~nm}$ - not shown) and yellow reflectance $(570 \mathrm{~nm}-$ Fig. S4a in Supplementary material), significant differences were found in both wavelengths among species $(p \leq 0.000)$ and irrigation doses $(p=0.033$ for $531 \mathrm{~nm}$ and $p=$ 0.022 for $570 \mathrm{~nm}$ ), but not for the interaction $(p \geq 0.50)$. Aleppo pine had a significantly higher green reflectance than the other pines, with slightly greater values for the lower watering. Similar results were obtained for red reflectance $(670 \mathrm{~nm})$, where significant differences were also found among species ( $p \leq 0.000)$ but not for the irrigation doses $(p=0.06)$ nor for the interaction $(p=0.56)$. Again, Aleppo pine had a significantly higher green reflectance than the other pines, without significant differences between irrigation treatments (Fig. S4b in Supplementary material). 
Tab. 5 - Correlation indices and their significance level (prob, in italic) among reflectances, reflectance indices, leaf-level gas exchange variables, water potentials and sap flow-derived variables: mdPot, midday water potential; pdPot, pre-dawn water potential; Sap Flow rate; An, net assimilation rate. Variables with only non-significant correlations have been omitted for clarity. $\left({ }^{*}\right): \mathrm{p} \leq$ $0.05 ;(* *): p \leq 0.01 ;(* *): p \leq 0.001$.

\begin{tabular}{|c|c|c|c|c|c|c|c|c|}
\hline Parameter & $\begin{array}{l}\text { mdPot } \\
\text { (Jun) }\end{array}$ & $\begin{array}{l}\text { Sap Flow } \\
\text { rate }\end{array}$ & $\begin{array}{l}\text { Monthly Flow } \\
\text { (Jun) }\end{array}$ & $\begin{array}{l}\text { mdPot } \\
\text { (Aug) }\end{array}$ & $\begin{array}{l}\text { Monthly Flow } \\
\text { (Aug) }\end{array}$ & $\begin{array}{l}\text { pdPot } \\
\text { (Sep) }\end{array}$ & $\begin{array}{c}\text { mdPot } \\
\text { (Sep) }\end{array}$ & $\begin{array}{l}\text { Monthly Flow } \\
\text { (Sep) }\end{array}$ \\
\hline green $531 \mathrm{~nm}$ & $-0.573^{* *}$ & -0.280 & -0.283 & $-0.538 * *$ & -0.353 & $-0.659^{* *}$ & $-0.623^{* *}$ & -0.237 \\
\hline prob & 0.003 & 0.186 & 0.180 & 0.007 & 0.090 & 0.001 & 0.001 & 0.264 \\
\hline yellow $570 \mathrm{~nm}$ & $-0.587^{* *}$ & -0.324 & -0.329 & $-0.570 * *$ & -0.400 & $-0.694^{* * *}$ & $-0.666^{* * *}$ & -0.282 \\
\hline prob & 0.003 & 0.122 & 0.116 & 0.004 & 0.053 & 0.000 & 0.000 & 0.182 \\
\hline red $670 \mathrm{~nm}$ & -0.523 ** & -0.327 & -0.343 & $-0.550 * *$ & -0.396 & $-0.721^{* * *}$ & $-0.667^{* * *}$ & -0.270 \\
\hline prob & 0.009 & 0.119 & 0.101 & 0.005 & 0.055 & 0.000 & 0.000 & 0.203 \\
\hline SWIR2 $2217 \mathrm{~nm}$ & -0.536 ** & -0.210 & -0.218 & $-0.562 * *$ & -0.294 & $-0.714^{* * *}$ & $-0.646^{* *}$ & -0.158 \\
\hline prob & 0.007 & 0.326 & 0.306 & 0.004 & 0.163 & 0.000 & 0.001 & 0.460 \\
\hline NDVI5 & 0.493 * & 0.294 & 0.319 & 0.513 * & 0.339 & $0.735^{* * *}$ & $0.645^{* *}$ & 0.235 \\
\hline prob & 0.015 & 0.163 & 0.129 & 0.011 & 0.105 & 0.000 & 0.001 & 0.270 \\
\hline PRI & 0.394 & $0.623^{* *}$ & $0.642 * *$ & $0.542^{* *}$ & $0.672^{* * *}$ & $0.673^{* * *}$ & $0.723^{* * *}$ & $0.592 * *$ \\
\hline prob & 0.057 & 0.001 & 0.001 & 0.006 & 0.000 & 0.000 & 0.000 & 0.002 \\
\hline NDII & $0.445 *$ & 0.157 & 0.175 & 0.458 * & 0.214 & $0.666^{* * *}$ & $0.571 * *$ & 0.104 \\
\hline prob & 0.029 & 0.465 & 0.415 & 0.025 & 0.315 & 0.000 & 0.004 & 0.630 \\
\hline swir1/red & 0.380 & $0.583^{* *}$ & $0.603^{* *}$ & 0.434 * & $0.604^{* *}$ & $0.645^{* *}$ & $0.643^{* *}$ & $0.541^{* *}$ \\
\hline prob & 0.067 & 0.003 & 0.002 & 0.034 & 0.002 & 0.001 & 0.001 & 0.006 \\
\hline An (Oct) & 0.345 & 0.444 * & 0.447 * & 0.475 * & 0.442 * & 0.517 * & $0.672^{* * *}$ & 0.428 * \\
\hline prob & 0.098 & 0.030 & 0.029 & 0.019 & 0.031 & 0.010 & 0.000 & 0.037 \\
\hline
\end{tabular}

For NIR reflectances, no statistical differences were found among species and water dose, except at $1190 \mathrm{~nm}$ wavelength, for which both the factor species $(p=$ $0.004)$ and irrigation ( $p=0.03)$ were significant. Again, P. halepensis showed greater reflectance with low irrigation than the other species (Fig. S4C in Supplementary material).

For SWIR1 (1650 nm) and SWIR2 (2217 $\mathrm{nm}$ ), Aleppo pine had significantly higher reflectance $(p=0.0012$ and $p=0.005$, respectively) with no differences between Stone and Scots pine. On the other hand, Aleppo pine had a significantly lower $\mathrm{NDVI}_{5}$ than the other two species ( $\mathrm{p}=$ 0.003 ).

The ANOVA of PRI showed significant differences between species ( $p=0.005)$, water dose $(p=0.009)$ and the interaction of both factors $(p=0.042)$. In this case, Scots pine had a higher PRI than the other two species and the higher the water availability, the higher the PRI (Fig. 3a).

No statistical differences were found for the SWIR1/SWIR2 ratio between species, irrigation treatment nor the interaction ( $p$ $=0.23$ ). On the other hand, The NDII of Aleppo pine (0.475) was significantly lower $(p=0.0365)$ than that of Scots pine (NDII = $0.599)$ and Stone pine (NDII = 0.633). Also, the NIR5/Red ratio index was significant for the species $(p=0.025)$, with higher values for both Stone pine (NIR5/Red = 7.219) and Scots pine $\left(N_{1 R} /\right.$ Red $\left.=6.849\right)$ than for Aleppo pine $\left(\mathrm{NIR}_{5} / \mathrm{Red}=4.089\right)$.

The SWIR1/Red ratio was significant for the species $(p \leq 0.001)$ and for the water dose $(p=0.007)$, but not for the interaction ( $p=0.20$ - Fig. 3b). The SWIR2/Red ratio was significant for the species $(p=$ $0.046)$ but not for the water dose $(p=$ $0.054)$ or for the interaction $(p=0.10)$.
Only this index has discriminated Scots gas exchange variables, water potentials pine from Stone pine with the high water- and sap flow-derived variables, showed siging dose (Fig. 3C). On the other hand, GEMI nificant correlation indices (Tab. 5). Green was not significant for any factor or for reflectance $(531 \mathrm{~nm})$ showed moderate their interaction $(p=0.253)$.

The multiple correlation analysis among $=-0.573$ ) of June $26^{\text {th }}$, being slightly higher reflectances, reflectance indices, leaf-level with the pre-dawn $(r=-0.659)$ and midday

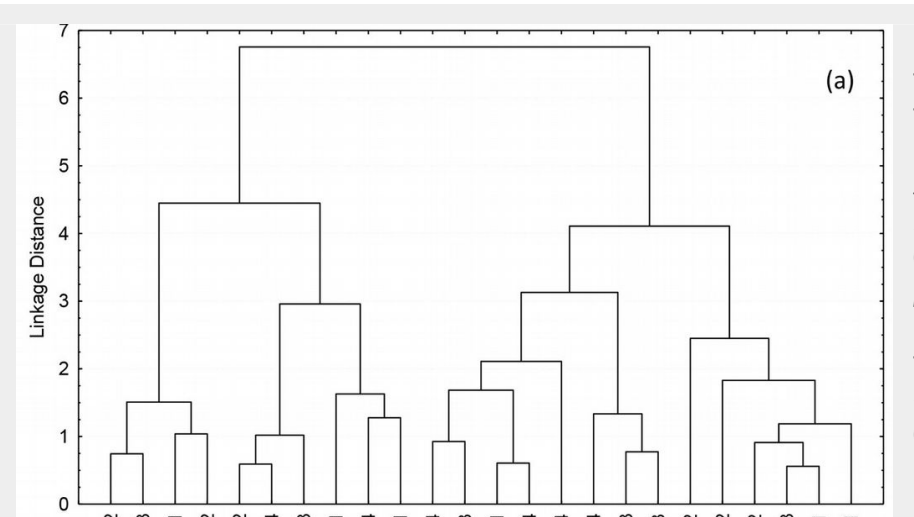

フํ.

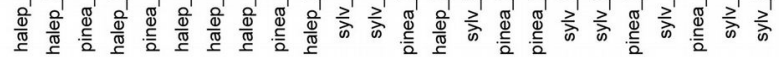

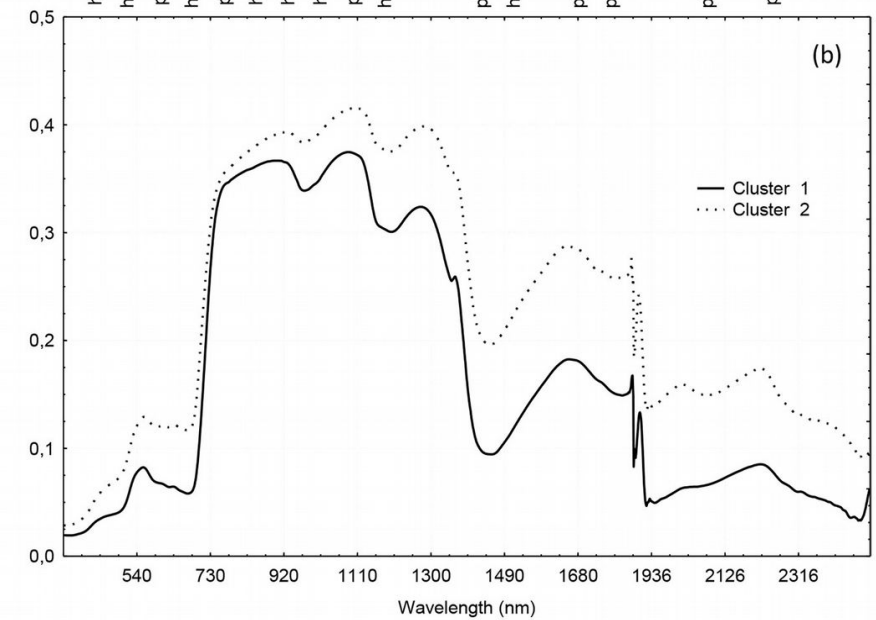

(b)

Fig. 4 - (a): Cluster analysis of the spectral signatures of Pinus sylvestris (sylv), P. halepensis (halep) and $P$. pinea (pinea) plants subjected to high (7 mm day $^{-1}$ ) and low (3.5 $\mathrm{mm} \mathrm{day}^{-1}$ ) irrigation; (b): Plot of means for clusters grouped by $k$-means $(k=2)$. Cluster 1: $P$. sylvestris $+P$. pinea $\mathrm{H}+\mathrm{P}$. pinea $\mathrm{L} 3+\mathrm{P}$. halepensis $\mathrm{H} 4$. Cluster 2: $P$. halepensis $+P$. pinea $\mathrm{L}-(P$. pinea $\mathrm{L} 3+P$. halepensis $\mathrm{H}_{4}$ ). Plants labeled with an $\mathrm{H}$ received high irrigation (7 mm day ${ }^{-1}$ ), and plants with label $L$ received low irrigation $(3.5$ $\mathrm{mm}$ day $\left.^{-1}\right)$. 
water potential $(r=-0.62)$ of September. This effect could be explained by the cumulative action of drought, which was more severe at the end of the summer. Yellow reflectance $(570 \mathrm{~nm})$ also showed a moderate association with the midday water potential of June $(r=-0.59-$ Tab. 5), with the September water potential at dawn ( $r$ $=-0.69)$ and at midday $(r=-0.66)$. Slightly better correlations with pre-dawn water potential of September were found for red (reflectance at $670 \mathrm{~nm}, \mathrm{r}=-0.72)$ SWIR2 $(r=$ -0.71) and for NDVI5 ( $r=0.73)$. For midday water potential in September, correlations were -0.67 for red $(670 \mathrm{~nm}),-0.65$ for SWIR2 and 0.645 for NDVI5 (Tab. 5).

PRI showed moderately good correlations with the total mean sap flow rate $(r=$ $0.62)$, the monthly sap flow in June ( $r=$ $0.64)$, the sap flow in August $(r=0.67)$, and also with the pre-dawn $(r=0.67)$ and midday $(r=0.72)$ water potentials of September (Tab. 5). The SWIR1/red ratio did not provide higher correlations than PRI for the same variables. On the other hand, no good correlations were found for SWIR2/ red, nor in general for other variables, such as E, $g_{s}$, WUE, IWUE and PPFD (data were omitted from Tab. 5 for the sake of clarity and simplification).

\section{Multivariate analysis of spectral signatures}

Spectral signatures of all 24 plants were grouped by cluster analysis. Different linkage rules were compared: single linkage, complete linkage, unweighted and weighted pair-group average, unweighted pairgroup centroid, weighted pair-group centroid, median and Ward's method. The best results were provided by the complete linkage rule, which discriminated two groups: one integrated by Aleppo pine plants (except for Aleppo pine plant $\mathrm{H}_{4}$ ) and Stone pine plants of the low irrigation treatment (except for Stone pine plant L3), and the other one formed by Scots pine plants, Stone pine plants of the high irrigation treatment and the two exceptions mentioned (Fig. 4a). Interestingly, there was no clear discrimination among Aleppo pine plants of either watering regime in the first group or among Scots pine plants of either irrigation treatments in the second group.

Similar results were obtained when spectral signatures were grouped by k-means (Fig. 4b). The average spectral signature of the cluster composed of Scots pine and highly watered Stone pine had a lower reflectance than the Aleppo pine and less watered Stone pine, for the spectral range of the study (from 350 to $2500 \mathrm{~nm}$ ). This pattern difference was highest in the SWIR range, though it is also apparent in the visible green and red, and in the NIR wavelengths (Fig. 4b).

\section{Discussion}

Ecophysiological responses of young plants of three Mediterranean pine species (Pinus sylvestris, P. pinea and P. halepensis) to low water availability have been investigated. We observed that the midday water potential was lower on June $26^{\text {th }}$ than on August $17^{\text {th }}$ and on September $24^{\text {th }}$ (Fig. 1b). This rise of the midday water potential that occurred between June and August suggests that pines closed stomata when aridity reaches a threshold. Similar results were obtained by Oliveras et al. (2003) in adult individuals of $P$. halepensis, which also showed a more pronounced decrease in midday water potential as compared with P. pinea, while pre-dawn water potentials were not significantly different. These results were also in agreement with those reported for minimum needle water potential measured in severe drought field conditions, $-2.6 \mathrm{MPa}$ for $\mathrm{P}$. halepensis, ca. -2.35 for P. pinea, and ca. $-2.25 \mathrm{MPa}$ for P. sylvestris (Martínez-Vilalta et al. 2004). Also, the water potentials for a $50 \%$ loss of xylem conductivity were, respectively, $-3.1 \mathrm{MPa}$, $-3.65 \mathrm{MPa}$ and $-3.57 \mathrm{MPa}$ (Martínez-Vilalta et al. 2004). The low overall variation of minimum water potential as a general rule in pine species implies that structural and physiological adjustments take place to maintain water potentials within relatively narrow limits, in agreement with an isohydric behavior. These results suggest a homeostatic behavior in pines to avoid extremely negative xylem water potentials and to prevent embolism by closing stomata and/or reducing leaf area (MartínezVilalta et al. 2004). Our results corroborate those considerations, with similar water potential values, though not so excessively low, indicating a moderate water stress in the low irrigated plants (Fig. 1b).

Pinus sylvestris had a higher mean sap flow rate than the other two species with more irrigation but the rate was reduced to approximately the same level as the other two pine species when less water was available. This behavior, again, may be explained either by a superior stomatal conductance or by a more efficient water transport capacity. Indeed, it has been reported that Pinus sylvestris shows a higher wood-specific hydraulic conductivity than $P$. halepensis and P. pinea (Martínez-Vilalta et al. 2004). Our observations partly confirmed that $P$. sylvestris plants had higher Al:As ratio, which is related to hydraulic conductivity, than $P$. pinea, but not significantly different from that of $P$. halepensis. On the other hand, Martínez-Vilalta \& Piñol (2002) found no differences among three pine species (Pinus sylvestris, P. nigra Arn. and $P$. pinaster Ait.) and their populations of NE Spain in maximum water transport capacity or vulnerability to embolism, corroborating that this homogeneity in hydraulic capacity is quite general in pines (Martínez-Vilalta et al. 2004). In Pinus canariensis Sweet, transpiration estimated by sap flow responded to canopy conductance, which was found to decline significantly with increasing evaporative demand and thus significantly reduced tree water loss, and this decrease was more pro- nounced during the soil drought (Brito et al. 2014). These considerations suggest that other mechanisms, i.e., stomatal regulation, may play a major role in adaptation and acclimatization to drought stress in pine species (Irvine et al. 1998).

During the adverse period of August, net assimilation was lower for all species, but as temperatures decreased, Pinus sylvestris showed a better capacity of recovery by a higher assimilation rate than the other pines. In contrast, in an experiment with Pinus halepensis, Klein et al. (2011) found slow rates of $\mathrm{CO}_{2}$ emission in trees under the highest drought intensity, i.e., $\approx 0.2$ $\mu \mathrm{mol} \mathrm{m} \mathrm{s}^{-1}$ at midday and $0.4 \mu \mathrm{mol} \mathrm{m} \mathrm{m}^{-1} \mathrm{~s}^{-1}$ in the late evening in the leaves of the less irrigated plants. Those plants later died, indicating that the $\mathrm{CO}_{2}$ uptake threshold had been surpassed and carbohydrate reserves were depleted (Klein et al. 2011). Similarly in P. sylvestris, $\mathrm{CO}_{2}$ depletion due to leaf mass reduction together with the tight stomatal closure in extremely dry conditions may lead to plant death, in spite of hydraulic adjustments that may allow short-term survival, for long-term resilience in response to drought is jeopardized (Poyatos et al. 2013). In our case, even in the driest period (August), average An was 0.33 umol $\mathrm{m}^{-2} \mathrm{~s}^{-1}$ for P. pinea, 1.24 for $P$. sylvestris, and 1.49 for $P$. halepensis, indicating a nonextreme water limitation. In agreement with our results, Flexas et al. (2014) reported positive An at a lower leaf water potential in $P$. halepensis than in $P$. pinea. Stomatal conductance followed the same pattern of An and E, as it was higher in October than in August. The interaction results indicate that $P$. halepensis regulates stomata better than the other pines tested, limiting conductance with water shortage in greater measure than Pinus pinea and $P$. sylvestris. Leaf stomatal conductance also decreased in response to drought, in $P$. halepensis near the Negev desert (Klein et al. 2011). These authors also observed that $g_{s}$ fell as midday leaf water potential declined and at $-2.8 \mathrm{MPa}$ conductance approached zero as a result of $99 \%$ stomatal closure. This tight regulation in $P$. halepensis is a characteristic of isohydric, water saving plant species, while $P$. pinea follows an intermediate pattern and P. sylvestris shows a tendency closer to the isohydric, water spending pattern, as indicated by the higher transpiration rates maintained by $P$. sylvestris with low water availability. On the other hand, this lower stomatal sensitivity of Pinus sylvestris may be in benefit of an increase in growth capacity. An, E and $g_{s}$ showed good correlations among them, and of $g_{s}$ with VPG ( $r=$ $-0.76-$ Tab. 1). The model response of $g_{s}$ to VPG described by Eamus \& Shanahan (2002) resembles our model in eqn. 5. Similar patterns of decreasing stomatal conductance with increasing VPG, while the correlation of net assimilation and transpiration with VPG are not so strong, have been described in Pseudotsuga menziesii 
(Mirb.) Franco (Meinzer 1982), supporting the hypothesis that stomata respond to the water vapor demand favoring $\mathrm{CO}_{2}$ uptake with respect to water loss.

Similar results of the relationship between solar radiation and sap flow were obtained in Pinus sylvestris (Gielen et al. 2010) and also in Pinus cembra L. of the Austrian Alps timberline, although VPG was the variable that best correlated with sap flow density (Wieser et al. 2014). A strong association was also found between sap flow-estimated transpiration and potential or reference evapo-transpiration in a Pinus halepensis stand with high soil water content, but this relationship was weaker with low water availability (Ungar et al. 2013). These results resemble our finding that sap flow correlated with ETo in the well irrigated plants, but the correlation coefficients were lower for all three species in the low irrigation treatment. Indeed, transpiration (estimated by sap flow) depends on both water availability and evaporative demand (ETo), and when water is a limiting factor, transpiration cannot keep pace with the ETo increase, as a probable consequence of stomatal closure.

Several authors have described pines, especially $P$. halepensis, as very sensitive to water deficit, showing a strong stomatal control under drought conditions (Baquedano \& (astillo 2006), in agreement with our observations. This adaptation mechanism of $P$. halepensis by means of extremely conservative water use (watersaver), contribute in this species to high drought resistance. On the other hand, Pinus halepensis is highly vulnerable to embolism, with a narrow safety margin between stomatal closure and xylem dysfunction as small as $0.3 \mathrm{MPa}$ (Klein et al. 2011). It has been hypothesized that $P$. halepensis has narrow tracheids and low hydraulic conductance to adjust to low water availability (Klein et al. 2011). This is probably why we observed lower sap flow and stomatal conductance rates than in the other species. Also, it has been reported that $P$. halepensis leaves are adapted to optimize stomatal conductance for avoiding carbon starvation as much as possible, resulting in leaf water potential approaching the danger zone for xylem collapse. That failure was usually avoided due to rapid stomatal responses. Therefore, $P$. halepensis is more efficient than most tree species in terms of using the carrying capacity of the xylem (Klein et al. 2011).

We also tested the relationships of leaf spectral reflectance with whole-plant transpiration, water relations and leaf-level gas exchange variables, finding that PRI was a better predictor of sap flow rate, i.e., whole plant transpiration, and of water potential than other spectral indices (Tab. 5). Although the PRI index was first proposed as a good indicator of photosynthetic activity and dissipation of excess energy not absorbed in the photochemical process (Garbulsky et al. 2011), we did not observe a statistical relationship of PRI with net assimilation. Inter-specific differences in xanthophyll content may affect the role of PRI as indicator in drought stress conditions (Filella et al. 2004). Nevertheless, we found a significant relationship between PRI and the water status associated to the irrigation treatment, in agreement with the findings of Ripullone et al. (2011). Similar results were obtained in Olea europaea, where trees subjected to irrigation treatment had a higher PRI as compared to control rain-fed olive trees (Marino et al. 2014). Also significant differences in PRI value have been observed when comparing several species, indicating that PRI is species-specific (Ripullone et al. 2011). In Quercus coccifera it was concluded that, contrary to early reports, PRI is a sensible, indirect, non-destructive water stress indicator, even in plants experiencing intense drought (Peguero-Pina et al. 2008), confirming our finding. Our results also are in agreement with those observed in Pinus sylvestris and $P$. nigra afforestations, where PRI showed a moderately good association with water potential and stomatal conductance (Hernández-Clemente et al. 2011), and in Olea europaea trees, which also showed a linear relationship between PRI and sap flux density (Marino et al. 2014), though the association was stronger in our case (Tab. 5). A good correlation between PRI and pre-dawn water potential has been described in the short term, in a pool of forest species, i.e., Arbutus unedo, several Quercus species, Castanea sativa, Fagus sylvatica and Populus $x$ euroamericana (Ripullone et al. 2011).

Characterization of ecosystem functioning and plant ecophysiology by means of associated spectral indices has been a major objective of remote sensing (Garbulsky et al. 2011). We identified simple spectral indices, such as PRI, NDVI, NDII, SR, SWIR/red and specific reflectances, for the discrimination of three dominant Pinus species present in many temperate and semi-arid Mediterranean ecosystems. We also found relationships between those spectral indices and ecophysiological features of the mentioned species, as tools opening possibilities for large-scale environmental studies. Previous studies reported the use of NIR and SWIR-based spectral indices associated with leaf water potential in Pinus contorta and P. coulteri (Cohen 1991). Close results were obtained in Olea europaea trees, also showing a good relationship between NDVI and water potential, for which $R^{2}=0.668$ was reported (Marino et al. 2014), similar to our results (Tab. 5). In contrast, Dzikiti et al. (2011) did not find significant correlations between water potential and various combinations of spectral reflectances, but the use of the first order spectral derivatives improved their results in orange trees.

\section{Conclusions}

In conclusion, ecophysiological responses of young plants of three Mediterranean pine species (Pinus sylvestris, P. pinea and $P$. halepensis) to water availability have been investigated. Two irrigation treatments were compared: a high water dose $\left(7 \mathrm{~mm} \mathrm{day}^{-1}\right)$ and a low dose $\left(3.5 \mathrm{~mm} \mathrm{day}^{-1}\right)$. Significant differences have been recorded in water potential, sap flow and leaf-level gas exchange variables and in their interactions. Our results revealed different responses to low water availability among the three pine species studied. All species showed the isohydric, drought-avoiding strategy which is common in the genus Pinus, maintaining relatively high water potentials. Nevertheless, P. halepensis showed a strong water-saving pattern, having a tight stomatal closure with drought, even at the expense of affecting $\mathrm{CO}_{2}$ uptake. On the other hand, stomatal regulation is less strict in Pinus sylvestris, closer to a water-spending behavior. Pinus pinea shows an intermediate behavior between the other two species. We may conclude that Pinus sylvestris may be endangered in a climate change context of more aridity in Mediterranean mountains. The search for inter- and intra-population variability, to explore more drought-tolerant individuals, more adapted ecotypes or other species should be considered in reforestation strategies. Alternatively, thinning may improve drought recovery and should be considered in forest management to improve drought tolerance in endangered forest species.

The spectral reflectance indices tested in this study may be valuable for fast, nonintrusive detection of water stress. We propose remotely sensed reflectance indices, in particular PRI, as promising predictive tools of the impact of drought on photosynthetic activity, water status and wholeplant transpiration.

Future applications of these techniques could be forest cover classifications in areas where Pinus sylvestris, P. pinea and P. halepensis are sympatric and need to be discriminated among them. We could discriminate the spectral signatures of $P$. sylvestris and $P$. halepensis by cluster analysis, and conclude that both species may be distinguished by hyperspectral sensors. On the other hand, $P$. pinea is intermediate between the other two species, and the hydric status of this pine can mimic the other two spectral patterns. With a high hydric availability, $P$. pinea spectral signature cannot be differentiated from that of P. sylvestris, and with less water, can be confused with P. halepensis. Presumably, in forested areas where $P$. halepensis and $P$. pinea are sympatric, the best moment for an adequate discrimination of the areas occupied by both species by hyperspectral imagery would be during the moist season. The findings of this experiment may help to quantify the impacts of early and midsummer water deficit on Mediterranean pines and evaluate their potential responses to future climate regimes. 


\section{Acknowledgements}

This work is the result of collaboration in the Moncloa Campus of International Excellence. EM carried out gas exchange measurements, MR and JM carried out the spectro-radiometry measurements, JZ was in charge of the nursery and laboratory measurements, EMF and JM performed the statistical analysis, AGG, BP and AGA conceived the study and JM helped to draft the manuscript. This work was supported by the Spanish Ministry of Industry, Project FIT330221200610 and Ministry of Education and Science, Project AGL-201017505. We thank Prof. Alicia Palacios and Victor Cicuendez for their scientific advice. We also thank Prof. J.C. Robredo for providing the meteorological data.

\section{Conflict of interests} est.

The authors declare no conflict of inter-

\section{References}

Baquedano FJ, Castillo FJ (2006). Comparative ecophysiological effects of drought on seedlings of the Mediterranean water-saver Pinus halepensis and water-spenders Quercus coccifera and Quercus ilex. Trees - Structure and Function 20 (6): 689-700. - doi: 10.1007/s00468006-0084-0

Brito P, Lorenzo JR, González-Rodríguez AM, Morales D, Wieser G, Jimenez MS (2014). Canopy transpiration of a Pinus canariensis forest at the tree line: implications for its distribution under predicted climate warming. European Journal of Forest Research 133 (3): 491-500. doi: 10.1007/s10342-014-0779-5

Cohen WB (1991). Response of vegetation indices to changes in three measurements of leaf water stress. Photogrammetric Engineering and Remote Sensing 57 (2): 195-202. [online] URL: http://ntrs.nasa.gov/search.jsp?R=199100 38559

Dzikiti S, Verreynne SJ, Stuckens J, Strever A, Verstraeten WW, Swennen R, Theron KI, Coppin $P$ (2011). Seasonal variation in canopy reflectance and its application to determine the water status and water use by citrus trees in the Western Cape, South Africa. Agricultural and Forest Meteorology 151 (8): 1035-1044. doi: 10.1016/j.agrformet.2011.03.007

Eamus D, Shanahan ST (2002). A rate equation model of stomatal responses to vapour pressure deficit and drought. BioMed Central Ecology 2: 8. - doi: 10.1186/1472-6785-2-8

Filella I, Peñuelas J, Llorens L, Estiarte M (2004). Reflectance assessment of seasonal and annual changes in biomass and $\mathrm{CO}_{2}$ uptake of a Mediterranean shrubland submitted to experimental warming and drought. Remote Sensing of Environment 90: 308-318. - doi: 10.1016/j.rse.20 04.01.010

Flexas J, Diaz-Espejo A, Gago J, Gallé A, Galmés J, Gulías J, Medrano H (2014). Photosynthetic limitations in Mediterranean plants: a review. Environmental and Experimental Botany 103: 12-23. - doi: 10.1016/j.envexpbot.2013.09.002 Garbulsky MF, Peñuelas J, Gamon JA, Inoue Y, Filella I (2011). The Photochemical Reflectance Index (PRI) and the remote sensing of leaf, canopy and ecosystem radiation use efficiencies: a review and meta-analysis. Remote Sensing of Environment 115: 281-297. - doi: 10.1016/j. rse.2010.08.023

Gielen B, Verbeeck H, Neirynck J, Sampson DA, Vermeiren F, Janssens IA (2010). Decadal water balance of a temperate Scots pine forest (Pinus sylvestris L.) based on measurements and modeling. Biogeosciences 7 (4): 1247-1261. - doi: 10.5194/bg-7-1247-2010

Granier A (1985). Une nouvelle méthode pour la mesure du flux de sève brute dans le tronc des arbres. [A new method for the measurement of sap flow in tree stems]. Annales de Sciences Forestieres 42: 81-88. [in French] - doi: 10.1051/ forest:19850204

Hardisky MA, Klemas V, Smart RM (1983). The influence of soil salinity, growth form, and leaf moisture on the spectral reflectance of Spartina alternifolia canopies. Photogrammetric Engineering and Remote Sensing 49: 77-83. Hernández-Clemente $R$, Navarro-Cerrillo RM, Suárez L, Morales F, Zarco-Tejada PJ (2011). Assessing structural effects on PRI for stress detection in conifer forests Remote Sensing of Environment 115 (9): 2360-2375. - doi: 10.1016/j. rse.2011.04.036

Irvine J, Perks MP, Magnani F, Grace J (1998). The response of Pinus sylvestris to drought: stomatal control of transpiration and hydraulic conductance. Tree Physiology 18: 393-402. - doi: 10.1093/treephys/18.6.393

Jacquemoud S, Verhoef W, Baret F, Bacour C, Zarco-Tejada PJ, Asner GP, François C, Ustin SL (2009). PROSPECT + SAIL Models: a review of use for vegetation characterization. Remote Sensing of Environment 113: 56-66. - doi: 10.1016/j.rse.2008.01.026

Klein T, Cohen S, Yakir D (2011). Hydraulic adjustments underlying drought resistance of Pinus halepensis. Tree Physiology 31 (6): 637-648. doi: 10.1093/treephys/tpro47

Manzanera JA, Martínez-Chacón MF (2007). Ecophysiological competence of Populus alba L., Fraxinus angustifolia Vahl. and Crataegus monogyna Jacq. used in plantations for the recovery of riparian vegetation. Environmental Management 40 (6): 902-912. - doi: 10.1007/s00267-0079016-z

Manzanera JA, Martin S, García-Abril A (2013). Functionality indicators for sustainable management. In: "Quantitative Techniques in Participatory Forest Management" (Martinez-Falero E, Martin-Fernandez S, Garcia-Abril A eds). CRC Press, Boca Raton, FL, USA, pp. 241-261. doi: $10.1201 /$ b15366

Marino G, Pallozzi E, Cocozza C, Tognetti R, Giovannelli A, Cantini C, Centritto M (2014). Assessing gas exchange, sap flow and water relations using tree canopy spectral reflectance indices in irrigated and rainfed Olea europaea L. Environmental and Experimental Botany 99: 43-52. doi: 10.1016/j.envexpbot.2013.10.008

Martínez-Vilalta J, Piñol J (2002). Drought-induced mortality and hydraulic architecture in pine populations of the NE Iberian Peninsula. Forest Ecology and Management 161: 247-256. doi: 10.1016/S0378-1127(01)00495-9

Martínez-Vilalta J, Sala A, Piñol J (2004). The hydraulic architecture of Pinaceae - a review. Plant Ecology 171: 3-13. - doi: 10.1023/B:VEGE. 0000029378.87169.b1

McDowell N, Pockman WT, Allen CD, Breshears DD, Cobb N, Kolb T, Plaut J, Sperry J, West A, Williams DG, Yepez EA (2008). Mechanisms of plant survival and mortality during drought: why do some plants survive while others succumb to drought? New Phytologist 178: 719739. - doi: 10.1111/j.1469-8137.2008.02436.x Meinzer FC (1982). The effect of vapour pressure on stomatal control of gas exchange in Douglas fir (Pseudotsuga menziesii) saplings. Oecologia 54: 236-242. - doi: 10.1007/BF00378398

Melzack RN, Bravdo B, Riov J (1985). The effect of water stress on photosynthesis and related parameters in Pinus halepensis. Physiologia Plantarum 64: 295-300. - doi: 10.1111/j.1399-305 4.1985.tb03343.x

Mitsopoulos ID, Dimitrakopoulos AP (2007). Allometric equations for crown fuel biomass of Aleppo pine (Pinus halepensis Mill.) in Greece. International Journal of Wildland Fire 16: 642647. - doi: 10.1071/WF06038

Montero G, Ruiz-Peinado R, Muñoz M (2005). Producción de Biomasa y fijación de $\mathrm{CO}_{2}$ por los bosques españoles [Biomass production and $\mathrm{CO}_{2}$ fixation in Spanish forests]. Monografías INIA, Serie Forestal, Madrid, Spain, pp. 270. [in Spanish]

Oliveras I, Martínez-Vilalta J, Jimenez-Ortiz T, Lledó MJ, Escarré A, Piñol J (2003). Hydraulic properties of Pinus halepensis, Pinus pinea and Tetraclinis articulata in a dune ecosystem of Eastern Spain. Plant Ecology 169: 131-141. - doi: 10.1023/A:1026223516580

Peguero-Pina JJ, Morales F, Flexas J, Gil-Pelegrín E, Moya I (2008). Photochemistry, remotely sensed physiological reflectance index and deepoxidation state of the xanthophyll cycle in Quercus coccifera under intense drought. Oecologia 156: 1-11. - doi: 10.1007/s00442-0070957-y

Pinty B, Verstraete MM (1992). GEMI: a non-linear index to monitor global vegetation from satellites. Vegetatio 101 (1): 15-20. - doi: 10.1007/ BFoo031911

Poyatos R, Aguade D, Galiano L, Mencuccini M, Martínez-Vilalta J (2013). Drought-induced defoliation and long periods of near-zero gas exchange play a key role in accentuating metabolic decline of Scots pine. New Phytologist 200 (2): 388-401. - doi: 10.1111/nph.12278 Ripullone F, Rivelli AR, Baraldi R, Guarini R, Guerrieri R, Magnani F, Peñuelas J, Raddi S, Borghetti M (2011). Effectiveness of the photochemical reflectance index to track photosynthetic activity over a range of forest tree species and plant water statuses. Functional Plant Biology 38 (3): 177-186. - doi: 10.1071/FP10078 Rondeaux G, Steven M, Baret F (1996). Optimization of soil-adjusted vegetation indices. Remote Sensing of Environment 55: 95-107. - doi: 10.1016/0034-4257(95)00186-7

Rouse JW, Haas RH, Schell JA, Deering DW, HarIan JC (1974). Monitoring the vernal advancement and retrogradation (Greenwave Effect) of natural vegetation. Type III Final Report, NASA Goddard Space Flight Center, Greenbelt, ML, USA, pp. 371. [online] URL: http://ntrs. nasa.gov/search.jsp?R=19740008955

Seager R, Ting M, Held I, Kushnir Y, Lu J, Vecchi G, Huang HP, Harnik N, Leetmaa A, Lau NC, Li C, 
Velez J, Naik N (2007). Model projections of an imminent transition to a more arid climate in southwestern North America. Science 316: 11811184. - doi: 10.1126/science.1139601

Snyder R, Pruitt W (1985). Estimating reference evapotranspiration with hourly data. In: "California Irrigation Management Information System Final Report" (Snyder R, Henderson DW, Pruitt WO, Dong A eds.). Vol. 1. Chapter VII Land, Air and Water Resources Paper 10013-A, University of California, Davis, CA, USA, pp. 1-3. Suárez L, Zarco-Tejada PJ, Sepulcre-Cantó G, Pérez-Priego O, Miller JR, Jiménez-Muñoz JC, Sobrino J (2008). Assessing canopy PRI for water stress detection with diurnal airborne imagery. Remote Sensing of Environment 112: 560575. - doi: 10.1016/j.rse.2007.05.009

Tardieu F, Simonneau T (1998). Variability among species of stomatal control under fluctuating soil water status and evaporative demand: modelling isohydric and anisohydric behaviours. Journal of Experimental Botany 49: 419432. - doi: 10.1093/jxb/49.Special_Issue.419

Ungar ED, Rotenberg E, Raz-Yaseef N, Cohen S, Yakir D, Schiller G (2013). Transpiration and annual water balance of Aleppo pine in a semiarid region: implications for forest management. Forest Ecology and Management 298:
39-51. - doi: 10.1016/j.foreco.2013.03.003

Ustin SL, Gitelson AA, Jacquemoud S, Schaepman M, Asner GP, Gamon JA, Zarco-Tejada P (2009). Retrieval of foliar information about plant pigment systems from high resolution spectroscopy. Remote Sensing of Environment 113: S67-S77. - doi: 10.1016/j.rse.2008.10.019

Wieser G, Gruber A, Oberhuber W (2014). Sap flow characteristics and whole-tree water use of Pinus cembra across the treeline ecotone of the central Tyrolean Alps. European Journal of Forest Research 133 (2): 287-295. - doi: 10.1007/s10342-013-0760-8

Zarco-Tejada PJ, Berjon A, Lopez-Lozano R, Miller JR, Martin P, Cachorro V, Gonzalez MR, Frutos A (2005). Assessing vineyard condition with hyper- spectral indices: leaf and canopy reflectance simulation in a row-structured discontinuous canopy. Remote Sensing of Environment 99: 271-287. - doi: 10.1016/j.rse.2005. 09.002

\section{Supplementary Material}

Tab. S1 - Experimental design and plant size at the beginning of the experiment of the pines used in the experiment.
Tab. S2 - Vegetation indices tested in Pinus halepensis, $P$. pinea and $P$. sylvestris plants subjected to irrigation treatments.

Tab. S3 - Meteorological data summary of the test period as compared to the 19812010 period.

Fig. S1 - Daily mean meteorological data registered from June to September.

Fig. S2 - Transpiration rate and stomatal conductance of Pinus sylvestris, $P$. halepensis and $P$. pinea subjected to two irrigation regimes, measured in August 21 and October 3 .

Fig. S3 - Mean spectral signatures of $P$. sylvestris, $P$. halepensis and P. pinea plants subjected to high and low irrigation.

Fig. S4 - Visible and near-infrared spectral reflectances of $P$. sylvestris, P. halepensis and $P$. pinea.

Link: Manzanera_1748@supploo1.pdf 